\title{
O que você já deixou de fazer por ser mulher? Relato de uma experiência
}

\section{Michel Alves Ferreira}

maferreiragi@gmail.com Universidade Tecnológica Federal do Paraná (UTFPR), Curitiba,

Paraná, Brasil.

\section{Talita Ketylin Costa Cabral}

Paringer

t.costacabral@gmail.com Universidade Tecnológica Federal do Paraná (UTFPR), Curitiba,

Paraná, Brasil.

\section{Lindamir Salete Casagrande} lindasc@utfpr.edu.br Universidade Tecnológica Federal do Paraná (UTFPR), Curitiba,

Paraná, Brasil

\author{
RESUMO
}

O objetivo deste relato de experiência é apresentar uma análise sobre os depoimentos de mulheres que de alguma forma se relacionaram com a UTFPR, campus Curitiba, no mês de março de 2016. O estudo foi baseado nos painéis produzidos na intervenção desenvolvida pelo Núcleo de Gênero e Tecnologia - GETEC, durante o "Il Mês da Mulher da UTFPR Mulheres Vencendo desafios", onde as mulheres (e alguns homens) deixaram os seus relatos respondendo a seguinte pergunta: “O que você já deixou de fazer por ser mulher? Foram analisados os relatos dessas pessoas, especialmente as mulheres (alunas, professoras, técnicas administrativas, trabalhadoras terceirizadas, dentre outras) sobre suas experiências pessoais e institucionais, buscando evidenciar suas opiniões e interpretar suas falas sob a lente de gênero. Em um segundo momento, apresentamos os depoimentos colhidos junto às/aos organizadoras/es da intervenção para captar suas impressões sobre os impactos da atividade, por categorias. Com base nesta análise foi possível perceber a necessidade das mulheres têm de encontrar espaços nos quais possam manifestar suas opiniões, se expressar de forma livre e espontânea, espaços nos quais possam dizer o que realmente pensam a respeito de serem mulheres e as consequências de que este fato tem em suas vidas. A intervenção evidenciou a necessidade de criação de espaços que viabilizem, com maior frequência, este diálogo dentro da universidade.
\end{abstract}

PALAVRAS-CHAVE: Relações de gênero. Mulheres. Espaços de diálogo. Estereótipos. 


\section{INTRODUÇÃO}

Para Cecilia Maria Bacellar Sardenberg (2002), a produção de saberes com vieses feministas possibilitaram que surgissem questionamentos dos modos de se produzir ciência e tecnologia (C\&T) baseados na ciência moderna dita neutra, imparcial em seus pressupostos e assexuada, mas que na verdade, para a autora, esta ciência negou às mulheres serem sujeitas e participantes dos próprios saberes científicos e tecnológicos.

É importante destacar que, se a C\&T são frutos da ação humana e estão sujeitas a disputas de poder e normatividade em seus discursos, são também manifestações da cultura e reflexos do pensamento hegemônico dos grupos detentores do poder nas sociedades. A partir da cultura é que se estabelece o discurso normativo da sexualidade, imputando às sexualidades consideradas inferiores e/ou desviantes do modelo hegemônico masculino, branco, heterossexual, europeu uma série de restrições. Falando especificamente sobre mulheres destaca-se a construção e delimitação de espaços onde estas não podem ou tem dificuldades para adentrar, opinar, conviver, se manifestarem plenamente como sujeitos. Espaços onde frequentemente são desrespeitadas, mutiladas em seus corpos e silenciadas, pelo simples fato de serem classificadas na categoria universalizante mulher e não na categoria mulheres $^{1}$ na qual contempla-se a diversidade, ou seja, mulheres negras, indígenas, transexuais, lesbianas, muçulmanas, pobres, dentre outras estão inclusas. (BEAUVOIR, 1970; CARVALHO, 1998; FOUCAULT, 1977; LAQUEUR, 2001).

Considerando as referências citadas nos parágrafos anteriores, nosso objetivo central neste artigo se fundamenta em apresentar um relato reflexivo sobre os depoimentos de mulheres que de alguma forma se relacionaram com a UTFPR, campus Curitiba, no mês de março de 2016, em uma intervenção realizada pelo Núcleo de Gênero e Tecnologia ( $\mathrm{GeTec}$ ) nas dependências da própria universidade. Vale destacar que este relato é parte de uma ação coletiva das/dos pesquisadores/pesquisadoras do GeTec, às/aos quais agradecemos pela iniciativa, e tem como um de seus objetivos registrar e divulgar os resultados, impactos e relevância de intervenções como esta no meio estudantil.

Como percurso metodológico, o relato de experiência foi elaborado a partir de dois elementos. O primeiro deles se tratou da coleta e agrupamento por categorias de 408 depoimentos e comentários, escritos livremente por mulheres e homens em um mural montado pelo GeTec, no pátio da UTFPR. Esta ação fez parte da campanha promovida pelo grupo de pesquisa, em sua segunda edição e tendo como título "Il Mês da Mulher da UTFPR: Mulheres Vencendo Desafios". A programação desse mês abarcou seminários, mesas redondas, debates, lançamento de livros e a intervenção do mural com a pergunta título: "O que você já deixou de fazer por ser mulher?". O segundo elemento componente do percurso metodológico foi composto por depoimentos coletados de sete das 12 pesquisadoras/pesquisadores do GeTec que participaram diretamente das ações. Foram excluídas/o as autoras e o autor deste relato de experiência, e duas pesquisadoras que não responderam às perguntas encaminhadas em formulário virtual durante o prazo estipulado, em julho de 2016. São trazidas para este relato algumas respostas a esta pesquisa. 
Com relação à organização deste relato de experiência, o mesmo está disposto em quatro pontos após esta introdução: o primeiro e segundo discorrem sobre os pressupostos teóricos norteadores e as características da intervenção. Já o terceiro destaca os resultados e discussões obtidos pelos materiais de pesquisa coletados. No último ponto, serão feitas as considerações finais.

\section{PRESSUPOSTOS NORTEADORES}

O surgimento de tecnologias e o avanço histórico da ciência, no período da modernidade, permitiram que os grupos produtores de conhecimento das sociedades ocidentais pudessem ter o controle e domínio efetivo sobre a natureza, de forma que elementos da biologia, medicina e psicanálise se tornaram cada vez mais pertinentes para a produção de discursos normativos de controle dos corpos. Soma-se a este espectro a moral e ética cristãs à produção de códigos de normas para corpos educados no sentido do que os sujeitos podem ou não fazer e se expressar nos espaços públicos e privados (CARVALHO, 1998; CÉSAR, 2010; FOUCAULT, 1977).

Embora com o avanço dos movimentos sociais do século XX, notadamente os movimentos feministas e de gênero, que questionaram os modelos de corpos educados do período da modernidade, ainda se percebe hoje, nos diferentes espaços da sociedade, especialmente na escola e na universidade, elementos de controle desses corpos em sua própria gênese: disposição de lugares de convívio e ensino, limites de trânsito dos sujeitos, formação de docentes voltada à produção de pessoas ideais à determinados grupos detentores de poder da sociedade, separação desses sujeitos de acordo com sua capacidade cognitiva ou ainda a separação pelo gênero e sexualidades constituídas/percebidas (ALMEIDA; LUZ, 2014; CASAGRANDE; LIMA E SOUZA, 2015; CASAGRANDE; CARVALHO, 2014; CÉSAR, 2010; FOUCAULT, 1977).

Assim, a presença e participação das mulheres na sociedade em geral e, também em espaços frequentados majoritariamente por homens, se tornam espaços de resistência e de efetivação/equidade de direitos, conforme descreve Maria Amélia de Almeida Teles (2006) em seu texto sobre os direitos humanos das mulheres na sociedade.

A Universidade Tecnológica Federal do Paraná pode ser considerada como um exemplo de lugar de resistência e de equidade/efetivação de direitos, a partir da presença mulheres ao longo de sua história. Esta instituição surgiu em setembro de 1909 como escola de aprendizes e tinha um caráter assistencialista. Em sua gênese, era voltada à formação de meninos e direcionada a saberes técnico/pragmáticos para a época, não permitindo que meninas nela estudassem. Mesmo depois de ter se transformado em Centro Federal de Educação Tecnológica (CEFET/PR) nos anos setenta do século passado, a visibilidade das mulheres da instituição era pouco significativa e persiste nos dias de hoje, já como UTFPR.

Quando se pensa, por exemplo, em mulheres na docência no campus (Curitiba), as mesmas representam 34,31\% dos 752 docentes, ou seja, 258 são mulheres. Os demais 494 docentes são homens, correspondendo a $65,69 \%$ do quadro docente da instituição. Da mesma forma, as estudantes mulheres tendem a não optarem por cursos das ciências exatas e tecnológicas, e uma das razões 
pode ser o fato de não se sentirem representadas e tampouco acolhidas neste universo. É possível inferir que na própria gênese da universidade têm questões de gênero incutidas na concepção entendida de escola e, mais tarde, de universidade tecnológica. (FERREIRA; CASAGRANDE, 2016; LIMA FILHO, 2005; MUZI; LUZ, 2010; UTFPR, 2010).

Por essa razão, as mulheres que participaram da intervenção proposta pelo GeTec, questionaram a naturalização de atributos que reforçam estereótipos e a própria dominação masculina nos seus diferentes espaços de trânsito e convívio, inclusive dentro da UTFPR.

\section{CARACTERÍSTICAS DA INTERVENÇÃO}

A intervenção elaborada pelas/os pesquisadoras/pesquisadores do GeTec foi composta por três elementos: uma faixa com a frase título da intervenção, painéis de papel com canetas para a escrita das respostas livres e frases/situações motivadoras e/ou de experiências vividas por diferentes mulheres. Todos estes materiais foram dispostos no pátio central do campus Curitiba da UTFPR. A faixa foi colocada acima dos painéis e os cartazes pendurados em uma estrutura central de forma que ficaram pendentes na altura dos olhos de quem passava, conforme mostra a FIGURA 1. O fato dos cartazes ficarem no caminho e atrapalharem a passagem das pessoas pelo pátio não foi feita de forma proposital, entretanto causou um desconforto interessante. Era impossível passar por ali sem perceber o que estava acontecendo.

Figura 1 - Espaço de intervenção

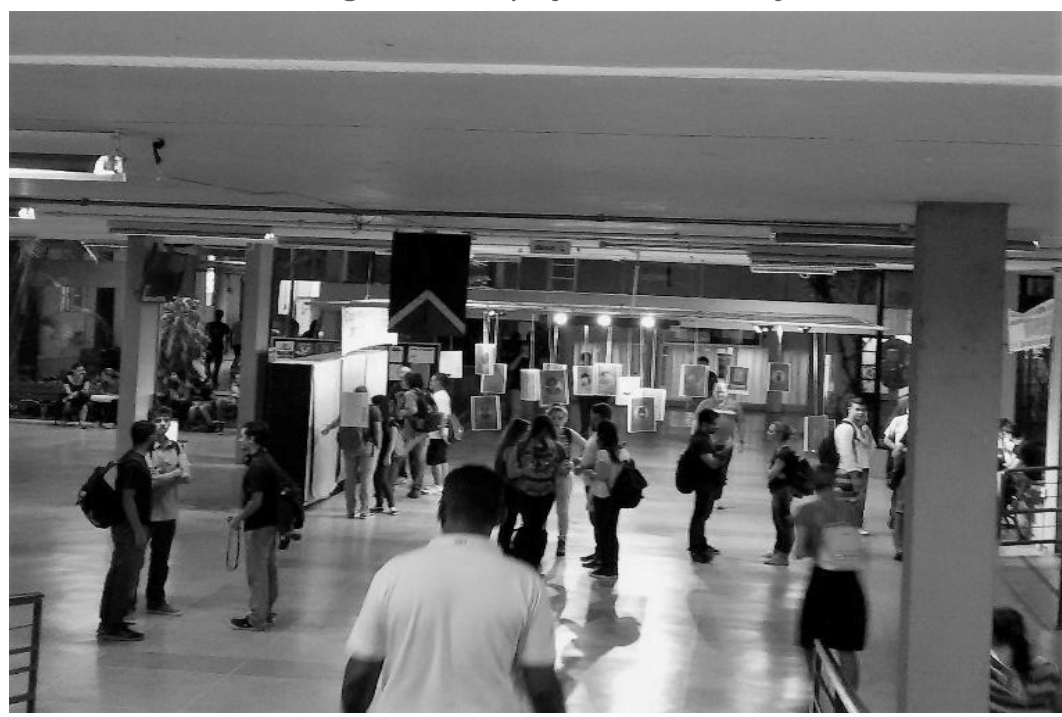

Fonte: Foto do/as autor/as (2016).

Foram escolhidas trinta imagens do projeto mulheres $^{2}$ da artista Carol Rossetti (2016) para a confecção dos cartazes motivacionais da intervenção. Vale ressaltar que essas imagens retratam diferentes situações do cotidiano experienciadas por mulheres, de forma que a própria autora as disponibiliza gratuitamente em seu site. 
Figura 2 - Instalações

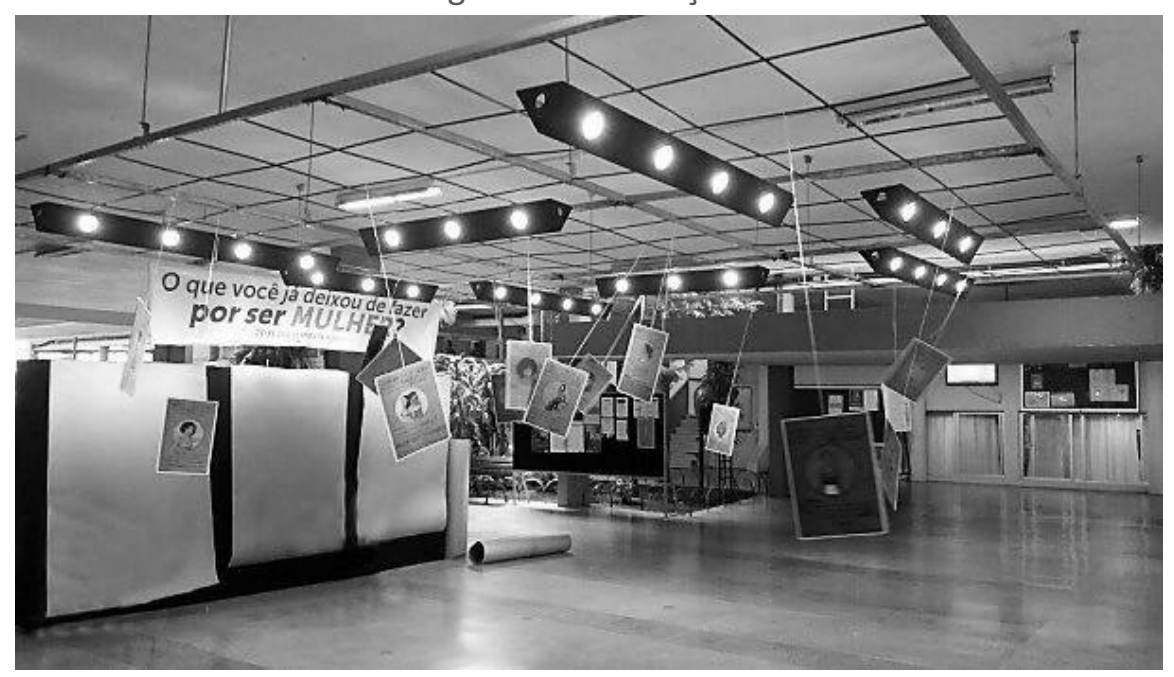

Fonte: Foto do/as autor/as (2016).

No final da intervenção foram recolhidos seis painéis de $120 \mathrm{~cm} \times 200 \mathrm{~cm}$ preenchidos com os depoimentos. Esses painéis foram fotografados e digitalizados de forma literal, frase por frase, totalizando 408 depoimentos. Deste total, 240 frases foram distribuídas em cinco categorias estabelecidas de acordo com os temas que mais apareceram nos painéis, sendo elas: Insegurança em espaços públicos; Vestuário; Educação e discriminação profissional; Estereótipos e "rótulos"; Esportes e jogos. As 170 frases que não se encaixaram nestas categorias foram armazenadas para análise em um posterior trabalho a ser construído. A FIGURA 3 apresenta um dos painéis elaborados durante a intervenção.

Figura 3 - Painel de intervenção

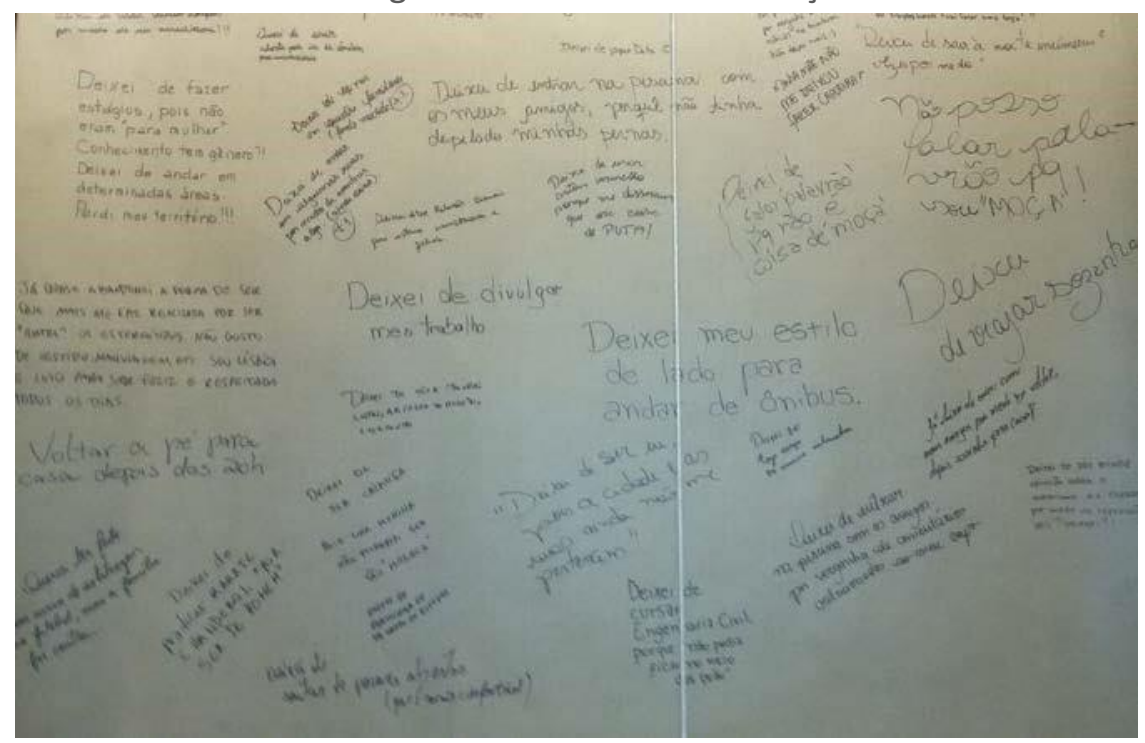

Fonte: Foto do/as autor/as (2016).

Além da participação das mulheres transeuntes da universidade, alguns homens deixaram suas manifestações, sendo umas em apoio à intervenção e outras de conotação depreciativa da atividade. Destaca-se que foram poucas 
intervenções depreciativas e uma das razões para isso pode ter sido a localização da intervenção. O local era de grande circulação de pessoas o que pode ter inibido a manifestação de pessoas que tinham opinião contrária à do grupo proponente da intervenção. Foram registradas também várias manifestações de incentivo e/ou indagação de depoimentos escritos anteriormente a participação.

Outro elemento que complementa o relato acerca desta intervenção diz respeito a pesquisa realizada com a comissão organizadora. A ela foi encaminhado um questionário online com as seguintes perguntas:

a) Sobre a intervenção "O que você já deixou de fazer por ser mulher?", na sua percepção, quais foram os principais resultados?

b) Qual a contribuição de atividades como esta para a minimização das desigualdades de gênero na sociedade atual?

c) Como você se sentiu por ter participado da programação e execução desta intervenção?

O objetivo central desta etapa foi registrar as percepções e impressões das/dos organizadores/as sobre a intervenção em si e as pessoas que registraram seus depoimentos, visto que as/os pesquisadoras/es se revezaram no pátio para entregar a programação do evento realizado pelo GeTec e com isso puderam observar as ações e reações das pessoas diante da intervenção.

\section{RESULTADOS OBTIDOS NO PROCESSO DE REALIZAÇÃO DA INTERVENÇÃO}

A primeira categoria, "insegurança em espações públicos", foi composta por 55 depoimentos das 240 frases selecionadas. Sobretudo, estes relataram o medo que as mulheres sentem em andar e viajar sozinhas, assim como sobre a incidência de assédios ocorridos quando tentaram realizar tais atos. Uma das ilustrações (FIGURA 4) expostas nos cartazes de autoria da artista Carol Rosseti (2016) representava esta vivência.

As cinco frases, consideradas por nós, como mais significativas foram:

Andar sozinha a noite.

Deixei de voltar tarde de festas.

Milhares de vezes deixei de sair sozinha.

Deixei de fazer um curso a noite, porque fiquei com medo de pegar ônibus e caminhar sozinha para casa, já que a aula terminaria depois das $22 h$.

Deixei de sair e pegar taxi sozinha. 
Figura 4 - Assédio

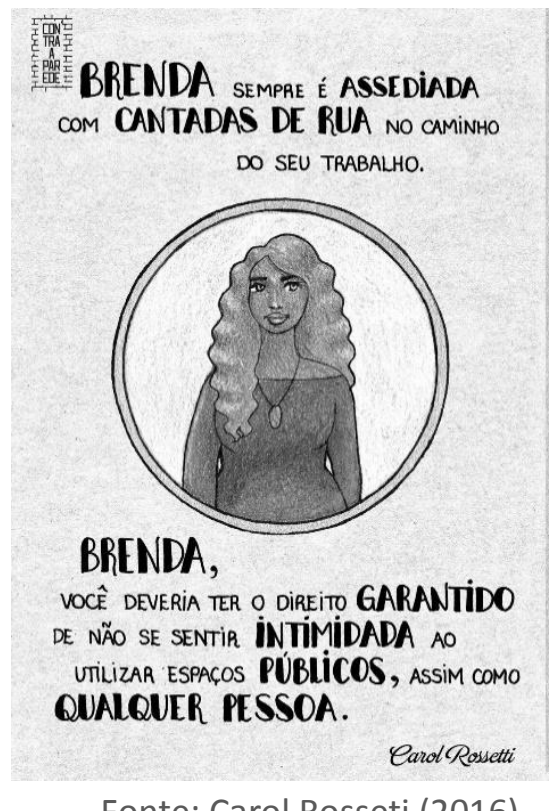

Fonte: Carol Rosseti (2016).

É possível inferir que essa insegurança percebida pelas mulheres nos espaços diz respeito à cultura de violência de gênero, ao qual se naturaliza as diferentes formas de violência contra a mulher. Estas violências podem ser de ordem física, psicológica, cultural, social, econômica, dentre outras. Dessa forma, a naturalização incute a cultura do medo nos diferentes grupos sociais que constituem as minorias, neste caso, as mulheres (TELES, 2006).

Percebe-se que estes depoimentos evidenciam que o fato de ser mulher limita sua capacitação profissional e de lazer. Mesmo um ambiente no qual deveriam se sentir seguras como o taxi se apresenta como uma ameaça para as mulheres. Destaca-se que este receio é pertinente pois inúmeros casos de violência contra a mulher ocorrem no trajeto de casa para a escola, para o trabalho, em retorno de festas, enfim, nos deslocamentos dessas mulheres. Os depoimentos evidenciam que o direito de ir e vir não é assegurado para as mulheres ${ }^{3}$.

Com relação ao tema "vestuário", foram destacados em 58 depoimentos. Os relatos trazem questões que apontam a insatisfação das mulheres frente às exigências da sociedade referente ao vestuário feminino, condicionando-as a adotar determinados tipos de roupas para supostamente evitar assédios e/ou discriminação. Também é possível dizer que essa categoria corrobora com a cultura de violência de gênero sofrida pelas mulheres e relatada no texto de Teles (2006, p. 35-36). Para a autora, tão importante quanto o Estado e sociedade garantirem a inalienação dos direitos humanos dos cidadãos e cidadãs, e a formalização dos direitos das minorias a partir das leis e de práticas efetivas, destaca-se que "[..] o reconhecimento formal exige, contudo, ações contundentes para viabilizá-los". Um elemento não está dissociado do outro na efetivação dos direitos femininos. Eis as cinco frases escolhidas da categoria:

De usar as roupas que eu quero. Meu namorado não acha certo.

Deixei de usar tipos de roupas por causa dos olhares. 
Deixei de sair com roupas curtas, justas.

Deixei de usar roupas frescas no calor por não estar depilada.

Deixei de usar roupas curtas, para não parecer puta.

Figura 5 - Vestuários

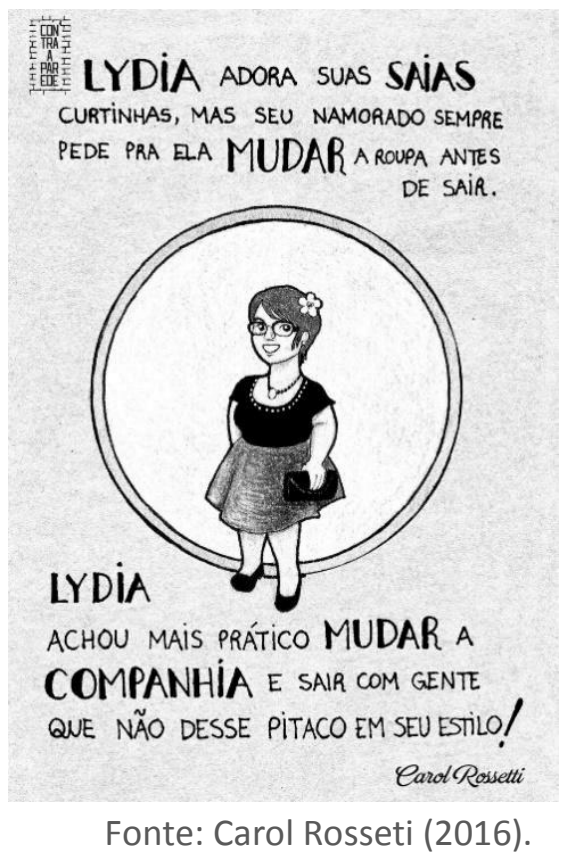

É possível perceber, na primeira fala, que a opinião do namorado faz com que a depoente deixe de usar as roupas de sua preferência. Neste depoimento fica evidente que o namorado se sente no direito de decidir o que ela deve ou não usar, o que nos leva a deduzir que esta intervenção machista pode ocorrer também em outros aspectos, como dizer o que ela deve ou não fazer, sentir, falar. Em muitos crimes cometidos por maridos ou companheiros, namorados a justificativa para tal fato e porque a mulher não fez o que ele determinou, ou seja, esta depoente pode, futuramente, ser vítima de outros tipos de violências ${ }^{4}$ além desta que ela já sofre.

A associação do tipo de roupa com a sexualidade ou a forma de viver a sexualidade das mulheres também é motivo para justificar a violência contra as mulheres. Isso se evidenciou no depoimento "Deixei de usar roupas curtas, para não parecer puta." Nesta frase fica evidente que não basta às mulheres terem comportamento sexual adequado aos padrões da sociedade, tem que parecer, transparecer este padrão.

Na terceira categoria, intitulada "educação e discriminação profissional", foram recuperadas 22 frases. Chamou a atenção nesta categoria os estereótipos imputados às depoentes, no sentido de que seus/suas próprios/as companheiros/as, família e demais pessoas de convívio reforçavam atributos deterministas e excludentes de que certos ofícios não foram feitos para mulheres. Às que insistiram, uma série de elementos dificultam a sua permanência, como cuidado com os filhos/as, casa, companheiros/as. 
Figura 6 - Educação e discriminação profissional

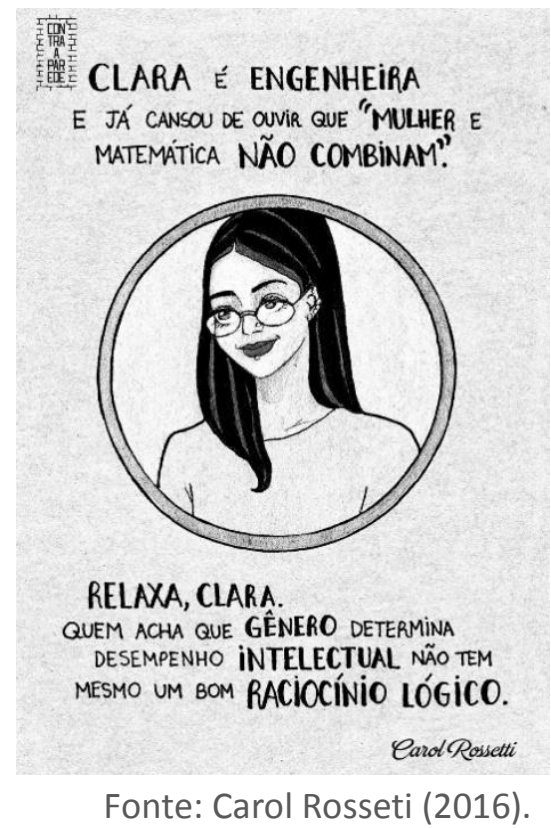

Além de corroborar para a cultura de violência de gênero, a discriminação relatada nesta categoria contribui para a invisibilização das poucas mulheres que adentram em determinados ofícios e saberes da sociedade que são construídos e percebidos como reduto dos homens. Estes resultados corroboram com os resultados encontrados por Lindamir Salete Casagrande e Ângela Maria Freire de Lima e Souza (2015) em pesquisa com estudantes de duas universidades federais brasileiras. As frases escolhidas nesta categoria são:

Deixei a área de mecânica industrial porque ao entregar currículos havia sempre vagas masculinas.

Deixei de concluir minha faculdade em dia quando minha filha nasceu, porque a sociedade machista dá o direito da mulher ficar em casa 6 meses e ao homem só 5 dias. Fossem 6 meses para a mãe e pai tudo seria dividido por igual! Direitos iguais, deveres iguais! E você ainda ficaria 6 meses fora.

Deixei de me alistar no exército.

Deixei de pegar um trabalho como supervisora de obras porque o dono da empresa queria um homem para esta função.

Já deixei de conseguir um estágio por ser somente para homens.

Meus pais não me deixaram estudar por ser mulher.

Como é possível perceber, o fato de ser mulher interfere tanto na formação quanto na inserção das mulheres no mercado de trabalho. Não é demais lembrar que uma parcela significativa dos lares brasileiros tem como principal fonte de renda a mulher ${ }^{5}$, ao se limitar sua qualificação profissional, também se limita as condições de vida das famílias sustentadas por estas mulheres.

Cabe destacar a fala sobre os direitos a licença maternidade e paternidade. A depoente afirmou que caso "[...] Fossem 6 meses para a mãe e pai tudo seria dividido por igual!." Isso não é um resultado automático. O fato do pai ter direito 
a licença em período igual ao da mãe não significa que as tarefas com os cuidados do bebê sejam automaticamente divididas igualmente. Temos uma construção cultural de que os afazeres domésticos são de responsabilidade das mulheres, ou seja, para que o resultado esperado pela depoente fosse alcançado haveria a necessidade de mudança cultural e não somente na legislação.

Figura 7 - Estereótipos e rótulos

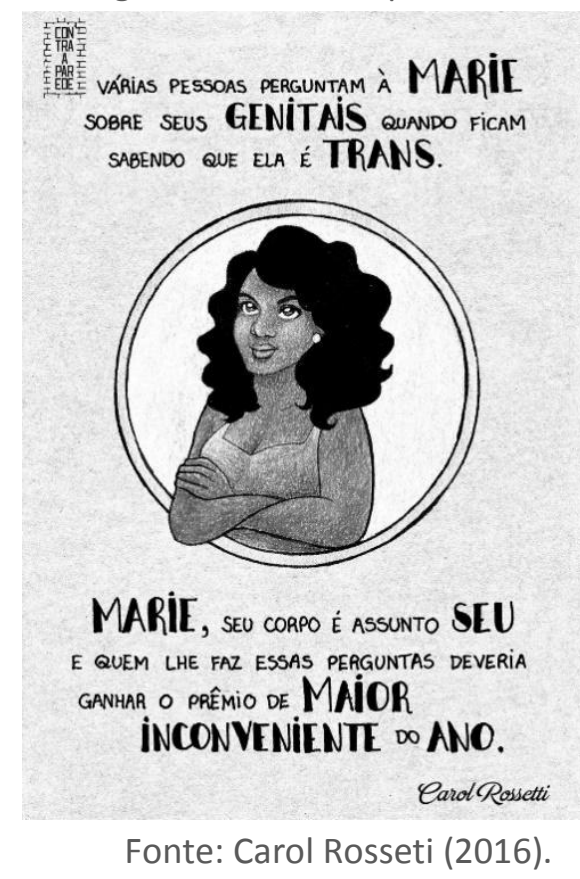

Com relação a quarta categoria, intitulada "estereótipos e rótulos", destacaram-se 72 frases, sendo a maior das cinco categorias, são reproduzidas seis delas. É interessante perceber que esta categoria tem elementos que a sociedade ocidental, influenciada não somente pela ciência e tecnologia, mas também pela doutrina cristã, considera como moral ou amoral, assim como os estereótipos desses elementos. Portanto o controle dos corpos, desde o século XVII, visa produzir códigos de sexualidades consideradas ideais para a sociedade em geral, de forma que homens e especialmente as mulheres sejam discretas nas suas sexualidades e formas de expressão, submissas aos seus companheiros e com vocação exclusiva para a casa e filhos. Ao mesmo tempo, também, são produzidas as sexualidades consideradas como desviantes ${ }^{6}$, especificamente das mulheres que não se encaixam no estereótipo bela, recatada e do $\operatorname{lar}^{7}$ (CÉSAR, 2010; FOUCAULT, 1977).

Eis as seis frases escolhidas:

Deixei de levar amigos homens em casa por medo dos vizinhos me acharem uma vadia.

Deixei de sentar com as pernas abertas e ficar sem camiseta no calor.

Deixei de usar cabelo curto porque é coisa de muleque.

Demorei para poder me expressar sexualmente, já que isso não é coisa de moça direita. 
Fazer xixi de pé.

Fui impedida de beber por ser mulher, porque isso me faria ser vista como mulher fácil.

A dificuldade de vivenciar sua sexualidade livremente também se fez presente nos depoimentos das mulheres da UTFPR. Este fato pode ser percebido em três dos seis depoimentos apresentados nesta categoria.

A última categoria trazida para este texto, intitulada "esportes e jogos", foram selecionadas para análise e construção deste texto 33 frases, das quais reproduzimos cinco.

Estas frases demonstraram as dificuldades sofridas pelas mulheres que adentram em esportes considerados masculinos, de forma que comumente a sexualidade das que insistem e conseguem quebrar estas barreiras e limites é questionada permanentemente. Novamente se percebem elementos debatidos por Maria Rita de Assis César (2010) e Michel Foucault (1977) em seus textos acerca do controle das sexualidades a partir da educação sistemática dos corpos e produção dos códigos éticos e morais imputados. As cinco frases apresentadas na sequência ilustram esta questão, notando a prevalência maior para o esporte futebol.

Deixei de fazer judô.

Deixei de jogar futebol.

Futebol é coisa de menino, filha minha não joga bola.

Minha mãe disse que não queria que eu jogasse futebol americano, pois é esporte de homem!

Minha mãe não me deixou fazer capoeira.

Figura 8 - Depoimento sobre esporte

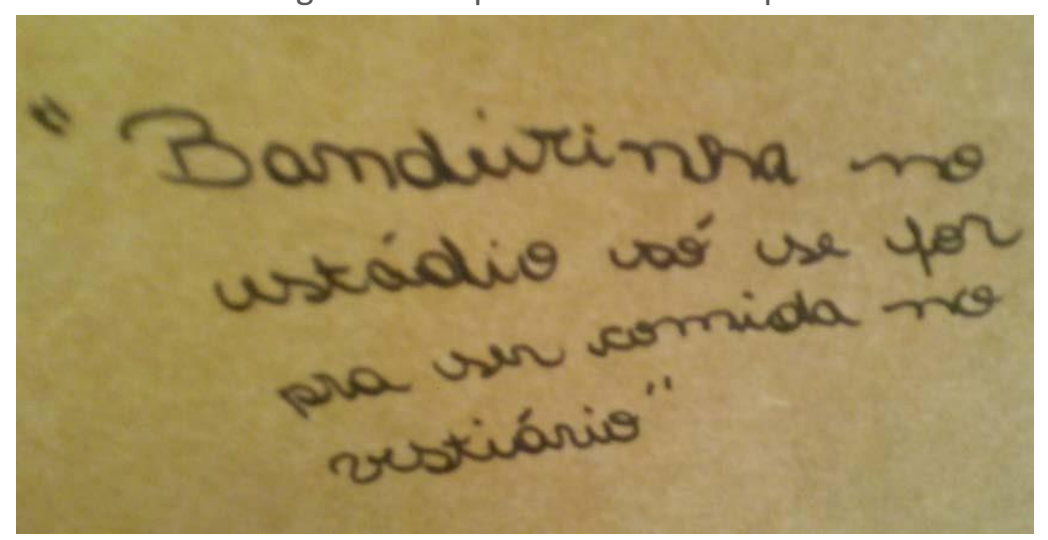

Fonte: Foto dos autores (2016).

A figura 8 ilustra como a questão da inserção de mulheres em esportes considerados masculinos, além de corroborar com a questão dos corpos educados debatidos por César (2010) e Foucault (1977), impute constantes ameaças àquelas que insistem em participar/reivindicar estes espaços, inclusive à sua integridade física e psicológica. Esta frase também serve para ilustrar os poucos depoimentos negativos deixados nos painéis. Como nos depoimentos não havia a identificação 
da/o depoente não é possível afirmar com certeza, mas, pelo teor do depoimento, infere-se que foi escrito por um homem. É uma frase nitidamente preconceituosa e machista.

Cabe destacar que o esporte é uma das formas de se preservar e às vezes resgatar crianças e adolescentes que vivem em comunidades com condições de infraestrutura precária tanto no que diz respeito a situação sanitária, quanto com relação a questão financeira, educacional, de segurança. Pode ser uma das formas de melhorar a condição financeira de famílias que vivem em condições precárias, pois quando um/a jovem se destaca em um determinado esporte pode fazer deste a sua escolha profissional. O esporte pode ainda se constituir numa forma de inserção dos/as jovens em sociedade. Limitar o acesso ${ }^{8}$ das meninas ao esporte significa limitar as possibilidades de mudança de perspectiva de futuro para muitas meninas/moças/mulheres.

\section{IMPRESSÕES DAS/DOS PARTICIPANTES DA COMISSÃO ORGANIZADORA DA ATIVIDADE}

Com relação às respostas dadas pelas pessoas ${ }^{9}$ que participaram da organização desta atividade, cabe destacar o consenso nas respostas do efeito positivo da intervenção realizada no pátio principal da UTFPR como primeira impressão. Outro elemento destacado nas respostas diz respeito aos aspectos emocionais, especialmente das mulheres da comissão organizadora, talvez pelo fato de se verem nos depoimentos das mulheres da UTFPR uma vez que fazem parte deste universo. Os excertos apresentados na sequência são trechos de respostas a terceira pergunta do questionário "Como você se sentiu por ter participado da programação e execução desta intervenção?":

Ainda que tentemos discutir "racionalmente" acerca da questão, é difícil não se afetar com a intervenção, mesmo tendo acompanhado sua construção desde o início. Intervenções e construção de conhecimento que nos afetam são as mais significativas, na minha opinião (Jyoti. Grifos da respondente)

Intrigada com as respostas, especialmente as desrespeitosas, aparentemente feita por homens - o que só afirma a importância desse tipo de intervenção na sociedade em geral e na UTFPR em particular (Tamires).

Determinado. Determinado a provocar, principalmente os homens. Por ser homem, sei o quanto esse tipo de informação causa incômodo e uma "explosão" de sentimentos e sensações, seguidas por uma desconstrução, reflexão e reconstrução da nossa masculinidade $e$ subjetividade enquanto homem, pelo tempo em que trabalho com questões de gênero e estudos feministas, já estou mais acostumado (mas não livre), e gostei da oportunidade de causar esse desconforto a outros homens. A zona de conforto que nosso sexo nos proporciona é um câncer na luta pela igualdade; mulheres, "provoquem-nos"! (Eduardo, grifos do respondente).

A identificação das angústias partilhadas nos murais pelas mulheres, assim como as palavras de provocação escritas por quem contestou a atividade despertou sensações díspares na equipe: ao mesmo tempo em que se sentiram 
bem em realizar uma atividade dessa natureza em uma universidade tecnológica, se solidarizaram pelos relatos escritos de violências sofridas. Essas sensações corroboram com Teles (2006), quando a autora argumenta que a ideia de violências contra as mulheres é, em sentido amplo e restrito, uma violação grave dos direitos e garantias fundamentais de todos os cidadãos de um país, especialmente quando dentro de instituições se reproduzem estereótipos afetivos, cognitivos e morais de maneira misógina, sexual e cultural depreciativas, xenofóbica, de capacidade cognitiva e, por fim, raciais.

Para Teles (2006, p. 38): "quando falamos em direitos humanos (estudos, questão, relações ou políticas) sob a perspectiva de gênero, adotamos o conceito antropológico". Esse conceito da autora tende a desvelar as características negativas imputadas às mulheres, de maneira que as respostas dos murais e da própria equipe corrobora o argumento de Teles (2006), o que vai de encontro com a segunda pergunta do formulário: "Qual a contribuição de atividades como esta para a minimização das desigualdades de gênero na sociedade atual? ".

De acordo com as respostas, foi possível perceber que a equipe concorda que atividades como a intervenção realizada evidencia as desigualdades de gênero sofridas pelas mulheres, mesmo no ambiente acadêmico.

Possibilidade de que toda a comunidade acadêmica (servidores, funcionários, estudantes) da instituição venha a refletir sobre a violência contra a mulher. Principalmente olhe e reflita sobre atitudes naturalizadas socialmente e que de alguma forma perpetuam desigualdades de gênero (Cristiana).

Outra respondente pondera acerca dos efeitos gerados pela atividade. Embora a contribuição em si seja positiva, para a respondente Jyoti, as possibilidades de mudança é que são oportunidades para buscar uma reflexão efetiva nos espaços de convívio. Segue sua explicitação:

Quanto à minimização direta destas desigualdades, creio que a contribuição é pouca. O que esta intervenção gera é a reflexão sobre o tema. Destas reflexões é que vislumbro as possibilidades de mudanças. Resta saber o que faremos com as reflexões suscitadas (Jyoti).

É possível inferir, com base no depoimento de Jyoti, que as possibilidades de mudanças contra as violências de gênero devem ser pensadas de forma coletiva, de forma que os/as protagonistas das ações de mudança sejam as próprias minorias, neste caso, as mulheres.

\section{AGRADECIMENTOS E CONSIDERAÇÕES FINAIS}

Este trabalho foi fruto de uma produção e construção coletiva e parte das atividades realizadas durante o mês da mulher de 2016 na UTFPR. A intervenção envolveu dezenas de pessoas e entidades (da própria universidade e comunidade externa), às quais registra-se o apreço e agradecimento de todas/os envolvidas/os. 
A análise dos resultados da intervenção, considerando o grande número de depoimentos, evidenciou que as mulheres precisam e querem espaços nos quais possam se manifestar livremente, falar sobre o que as oprime. Evidenciou que ao longo da vida as estudantes, funcionárias, servidoras e demais mulheres que transitaram pela UTFPR no mês de março de 2016 sofreram micro violências ao longo de suas vidas. Estas violências camufladas como cuidado, preocupação, proteção, amor tem imposto limites ao desenvolvimento acadêmico, profissional e afetivo de muitas mulheres. Dificultam a progressão e ascensão de mulheres a carreiras e cargos mais valorizados social e financeiramente pela sociedade atual.

O que é importante destacar é que foram as mulheres, enquanto grupos de resistências, inseridas dentro dos movimentos sociais e feministas, especialmente ao longo de todo o século $\mathrm{XX}$, que problematizaram as discussões de sexo, sexualidade e gênero para dentro das instituições, conforme descrito por César (2010) em seu texto sobre o controle/disciplina dos corpos, e especialmente por Sardenberg (2002) no tocante à academia e a crítica feminista da ciência.

Foram essas mulheres inseridas nos movimentos sociais/feministas que forçaram questionamentos naturalizantes e deterministas presentes desde a concepção dos saberes científicos e tecnológicos. Foram elas que chamaram a atenção para que se estudasse e questionasse os porquês de elas serem tão poucas em espaços eminentemente masculinos, tal como grande parte dos cursos de engenharias da UTFPR, tal como descreveu Ferreira e Casagrande (2016) e Muzi e Luz (2010) em seus textos. Isto ficou evidente nos relatos, especialmente na categoria educação e discriminação profissional, quando uma das depoentes diz que desistiu da área de mecânica industrial porque era difícil a sua inserção no mercado do trabalho pelo fato de ser mulher e isto estar implícito na entrega de currículos.

Tal como a respondente Jyoti, se espera que este texto faça jus aos depoimentos registrados e as dores compartilhadas por estas mulheres. Esperase, também, que este relato seja um objeto de reflexão para se pensar em práticas efetivas de emancipação digna dos sujeitos em todas as instâncias da sociedade, a começar pela própria universidade. 


\title{
What have you done doing for being a woman? Report of an experience
}

\begin{abstract}
The objective of this report of experience is to present an analysis on the testimonies of women who somehow related to the UTFPR, campus Curitiba, in the month of March 2016. The study was based on the panels produced in the intervention developed by the Nucleus of Gender and Technology - GETEC, during the "II Women's Month of UTFPR - Women Winning Challenges", where women (and some men) left their accounts answering the following question: "What have you stopped doing for being a woman? The reports of these people, especially women (students, teachers, administrative techniques, outsourced workers, among others) were analyzed about their personal and institutional experiences, seeking to highlight their opinions and interpret their speeches under the gender lens. In a second moment, we present the statements made with the organizers of the intervention to capture their impressions about the impacts of the activity, by categories. Based on this analysis, it was possible to perceive the need for women to find spaces in which they can express their opinions, express themselves freely and spontaneously, spaces in which they can say what they really think about being women and the consequences of this Fact has in their lives. The intervention showed the need to create spaces that more often enable this dialogue within the university.
\end{abstract}

KEYWORDS: Gender relationships. Women. Dialogue spaces. Stereotypes. 


\section{NOTAS}

${ }^{1}$ As referências trazidas atestam que a concepção da categoria mulher pode ser considerado um construto cultural e social, hierarquicamente subjugado pela categoria homem. Embora a concepção inicial de mulher, especialmente de Beauvoir (1970), fosse universalizante em nosso entendimento, a mesma foi fundamental para o surgimento dos primeiros movimentos feministas dos anos 60 e 70 do século passado, além de correntes acadêmicas da sociologia, psicanálise, linguística e história, que se propuseram a estudar a categoria mulher. Esses estudos se ampliaram a partir do fim dos anos 70 nos Estados Unidos e Europa e procuraram interseccionar com diferentes espectros da sociedade, para além das sexualidades e de seus corpos. Por isso hoje é possível entender a categoria mulher como universalizante; a categoria mulheres contempla efetivamente as diversidades. (BEAUVOIR, 1970; BUTLER, 2003; FOUCAULT, 1977; LUGONES, 2011; RUBIN, 1985).

${ }^{2}$ Este projeto é composto de imagens criadas pela própria artista e publicadas na internet e em um livro. Tanto um material quanto o outro interseccionam gênero com outras categorias: etnia, sexualidade, necessidades especiais, comportamento. A consulta pode ser feita no endereço eletrônico: <http://www.carolrossetti.com.br/mulheres> e as imagens dos cartazes são disponibilizadas gratuitamente pela autora do projeto.

${ }^{3}$ Em entrevista à reportagem da BBC Brasil no dia 05 de janeiro de 2017, a filósofa Márcia Tiburi comenta acerca do feminicídio ocorrido em 01 de janeiro do mesmo ano na cidade de Campinas/SP, cometido pelo ex-companheiro de uma das vítimas. Das 12 pessoas mortas na festa de ano novo, 9 eram mulheres e uma era o filho do ex-casal, uma criança de oito anos. A carta deixada pelo assassino e publicada nas redes sociais online, justificando as razões de cometer tal ato, imputa a culpa à categoria mulheres. Para Márcia Tiburi, a suposta culpa atribuída pelo assassino recai especialmente às mulheres que contestam o machismo e misoginia estrutural na sociedade brasileira, de maneira que este indivíduo que cometeu tal crime pode ser considerado como um produto da cultura da violência de gênero impetrada às mulheres de um modo geral. Prova desse elemento pode ser visto na maneira como a Lei no 11.340 de 2006, mais conhecida como "Lei Maria da Penha", é referida pejorativamente pelo autor da chacina.

Para a socióloga Wânia Pasinato, da Universidade de São Paulo (USP), em entrevista ao El País no dia 2 de janeiro, falta uma efetiva aplicação das leis brasileiras que mitigam os efeitos da cultura de violências de gênero no Brasil. Na fala da socióloga entrevistada, o movimento conservador que assumiu o poder no país a partir de abril de 2016 contribui para que as discussões de gênero encontrassem maiores dificuldades de inserção na sociedade. Dessa forma, contribui-se ainda mais para que a intolerância contra as minorias ocorra no país. Já em 2015 é possível perceber esses indicativos de intolerância de gênero estrutural na sociedade, quando no dia internacional da mulher a então Presidenta Brasileira Dilma Vana Rousseff foi hostilizada em sua pessoa, online e em protestos no país durante e após o seu pronunciamento na televisão. Todos estes fatos recentes levantados demonstram as dificuldades sofridas pelas mulheres no seu trânsito em espaços públicos/privados. As notícias podem ser acessadas pelos links: <http://www.bbc.com/portuguese/brasil-38503326> (BBC BRASIL), 
<http://brasil.elpais.com/brasil/2017/01/02/politica/1483382488_219669.html> e<http://brasil.elpais.com/brasil/2015/03/09/politica/1425911342_272443.html $>$ (El País).

${ }^{4}$ Apresentamos como exemplo recente que corrobora com as análises dos depoimentos o movimento "Marcha das Vadias". Surgiu inicialmente na cidade de Toronto (Canadá) em 2011, como resposta à uma insinuação pejorativa, realizada por um policial canadense, acerca do vestuário de uma vítima de violência sexual. Este movimento se espalhou em várias cidades do mundo e cada representação local incute suas pautas próprias. A marcha das vadias de Curitiba/PR propõe representar todas as diversidades de mulheres e reafirma a luta contra a violência de gênero estrutural contra as minorias, inclusive em vestuários e naturalizadas pela sociedade em geral. Para saber mais sobre a marcha curitibana, acessar: https://marchadasvadiascwb.wordpress.com/2016/11/04/quem-somos/ e https://www.facebook.com/marchadasvadiascwb/about/.

${ }^{5}$ O Jornal Folha de São Paulo veiculou uma matéria em 04 de dezembro de 2015 que corrobora com esta afirmativa. Baseado no estudo do Instituto Brasileiro de Geografia e Estatística (IBGE) acerca dos indicadores sociais de 2014 no país, a Folha afirma que $38,7 \%$ das famílias brasileiras são chefiadas por mulheres. Esse dado é significativo, ao se comparar com a escolaridade e ganho das mulheres publicado na chamada Pesquisa Nacional por Amostra de Domicílios (PNAD) de 2014: homens com ensino superior do país ganham, em média, 33\% a mais do que mulheres com a mesma escolaridade. Os links podem ser acessados aqui: <http://www1.folha.uol.com.br/mercado/2015/12/1714906proporcao-defamilias-chefiadas-por-mulheres-chega-a-40-em-2014.shtml> (Matéria da Folha de São Paulo) e <http://biblioteca.ibge.gov.br/visualizacao/livros/liv94935.pdf> (estudo do IBGE).

${ }^{6}$ Foucault (1977) descreve as sexualidades consideradas como não ideais pela ciência, medicina, biologia, ética e moral cristãs do século XVII (e que de certa forma persistem ainda nos dias de hoje). Com ela, também são produzidos os estereótipos e os sujeitos desviantes, notadamente a partir do século XIX, se criando a criança sexualmente precoce, o depravado e sádico do sexo, a mulher histérica e louca, a mulher frígida, o homossexual.

${ }^{7}$ A polêmica gerada pela reportagem de Juliana Linhares da Revista Veja, sobre a matéria da hoje Primeira Dama brasileira Marcela Temer, veiculada em 18 de abril de 2016, ilustra o que César (2010) e Foucault (1977) discorreram em seus textos sobre as sexualidades, produção de sujeitos ideais e controle dos corpos, imputando papéis bem definidos para cada um. De forma que se propaga a ideia geral de que sujeitos fora desses papéis definidos podem ser vistos pela sociedade como abjetos. Embora não haja problema algum em ser recatada e do lar, a polêmica gira em torno da imposição que toda a categoria mulheres deva ter esses mesmos atributos para serem consideradas respeitáveis pela sociedade. Além do mais, de que tipo de recato estamos falando? E que lar é esse? Outro elemento pertinente diz respeito à bela, por ser uma construção subjetiva a cada indivíduo e/ou grupo social. Têm-se, assim, a criação desse estereótipo bela, recata e do lar de como uma mulher brasileira deve ser, fortemente contestada pelos movimentos sociais/feministas. O link da matéria da revista: <http://veja.abril.com.br/brasil/marcela-temer-bela-recatada-e-do-lar/>. 
${ }^{8}$ Conforme o Portal Brasil (2016), sítio do governo federal, as mulheres tiveram de conquistar, com lutas, o acesso a determinados esportes. De acordo com a reportagem de 08 de março de 2016, no período do Estado Novo de Getúlio Vargas se limitava determinados esportes às mulheres, fundamentado ao que se entende por "coisas/lugares de mulher", corroborando com a tecedura teórica constituída neste artigo, especialmente César (2010) e Foucault (1977). A reportagem completa pode ser acessada pelo link: <http://www.brasil.gov.br/cidadania-ejustica/2016/03/mulheres-brasileirastiveram-de-derrubar-a-exclusao-paraentrar-na-historia-do-esporte>.

${ }_{9}^{9}$ Para efeitos de preservação de identidade, todos nomes das/dos participantes foram substituídos, de forma que para os respondentes homens, foram escolhidos nomes aleatórios. Com relação às respondentes mulheres, foram escolhidos para este relato nomes de mulheres que simbolizam e/ou simbolizaram a luta contra a cultura de violência feminina em diferentes lugares. Dessa forma, surgiram Jyoti Singh, estudante de medicina indiana que foi estuprada e morta em 2012 por cinco homens e um menor de idade, sendo que o seu caso gerou penas mais duras contra o estupro na Índia e um documentário premiado intitulado Filhas da Índia; Tamires Gomes Sampaio, estudante negra de uma universidade privada paulistana que veementemente denunciou o racismo na instituição, sendo também a primeira negra a assumir a direção de um centro acadêmico; Cristiana Bento, delegada de polícia da cidade do Rio de Janeiro que assumiu a coordenação das investigações de um caso de estupro coletivo sofrido por uma adolescente carioca em maio de 2016, após afastamento do delegado que conduzia as investigações em razão de culpabilização da vítima. As notícias onde mencionam essas mulheres podem ser consultadas nos seguintes links: <http://www.bbc.com/portuguese/internacional36400156> (Jyoti Singh); <http://g1.globo.com/saopaulo/noticia/2015/10/pichacao-racista-e-encontradaem-banheiro-domackenzie-em-sp.html> (Tamires Gomes Sampaio) e <http://g1.globo.com/rio-dejaneiro/noticia/2016/06/policia-conclui-inqueritode-estupro-coletivo-no-rio-comsete-indiciados.html> (Cristiana Bento). 


\section{REFERÊNCIAS}

ALMEIDA, Kaciane Daniella. LUZ, Nanci Stancki. Educação sexual: uma discussão para a escola? Curitiba: Appris, 2014.

BARBOSA, Anne. Pichação racista é encontrada em banheiro do Mackenzie em SP. G1. São Paulo, 07 out. 2015. Disponível em: <http://g1.globo.com/saopaulo/noticia/2015/10/pichacao-racista-e-encontradaem-banheiro-domackenzie-em-sp.html>. Acesso em: 18 jan. 2017.

BBC BRASIL. Internacional. 0 estupro coletivo que chocou Índia e mudou lei: basta uma palavra para evocar o caso de estupro coletivo que chocou a Índia há quatro anos - levando a mudanças na legislação e, segundo especialistas, repercussões culturais no país. [27 mai. 2016]. Disponível em: <http://www.bbc.com/portuguese/internacional-36400156>. Acesso em: 18 jan. 2017.

BEAUVOIR, Simone de. O segundo sexo: fatos e mitos. Tradução de Sergio Milliet. 4.ed. São Paulo: Difusão Europeia do Livro, 1970.

BRASIL. PORTAL BRASIL: cidadania e justiça. Mulheres brasileiras tiveram de derrubar a exclusão para entrar na história do esporte. Disponível em: <http://www.brasil.gov.br/cidadania-e-justica/2016/03/mulheresbrasileirastiveram-de-derrubar-a-exclusao-para-entrar-na-historia-do-esporte>. Acesso em: 21 jan. 2017.

BUTLER, Judith. Problemas de gênero: feminismo e subversão da identidade. Tradução de Renato Aguiar. Rio de Janeiro: Civilização Brasileira, 2003.

CAROL ROSSETTI. O projeto mulheres. Disponível em: <https://www.carolrossetti.com.br/mulheres>. Acesso em: 21 ago. 2016.

CARVALHO, Marília Gomes de. Tecnologia e sociedade. In: BASTOS, João Augusto de Souza Leão de Almeida. Tecnologia \& interação. Curitiba: CEFET-PR, 1998, cap. 5, p. 89-102.

CASAGRANDE, Lindamir Salete; LIMA E SOUZA, Ângela Maria Freire de. Violência simbólica de gênero em duas Universidades Brasileiras. In: WANZINACK, Clóvis; SIGNORELLI, Marcos Claudio (orgs). Violência, gênero e diversidade: Desafios para a educação e o desenvolvimento. Rio de Janeiro: Autografia, 2015, p. 79108.

CASAGRANDE, Lindamir Salete; CARVALHO, Marília Gomes de. Relações de gênero nas aulas de matemática: perceptíveis ou ocultas? Cadernos de Gênero e Tecnologia. Curitiba: n. 31-32, jul./dez. 2014, p. 36-48.

CÉSAR, Maria Rita de Assis. A (des) educação do corpo: corpos contemporâneos e lugares de transgressão. Vivência: revista de antropologia. Natal: v. 35, n. 1, 2010, p. 161-168.

FERREIRA, Michel Alves. CASAGRANDE, Lindamir Salete. Mulheres na

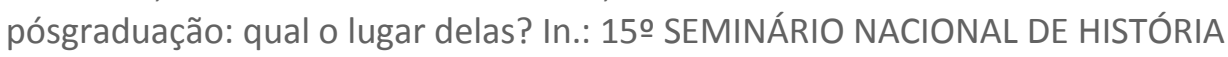
DA CIÊNCIA E DA TECNOLOGIA. 15.. Florianópolis, Anais Eletrônicos... Florianópolis, 2016. Disponível em: <http://www.15snhct.sbhc.org.br/resources/anais/12/1470063617_ARQUIVO_A RTIGOSNHCTVERSAOFINAL.pdf $>$. 
FOUCAULT, Michel. História da sexualidade I: a vontade do saber. Trad. De Maria Thereza da Costa Albuquerque e José Augusto Guillon de Albuquerque. Rio de Janeiro: Edições Graal LTDA, 1977.

INSTITUTO BRASILEIRO DE GEOGRAFIA E ESTATÍSTICA. Pesquisa nacional por Amostra de domicílios: síntese de indicadores 2014. Rio de Janeiro: IBGE, 2015.

LAQUEUR, Thomas Walter. Inventando o sexo: corpo e gênero dos gregos a Freud. Tradução de Vera Whately. Rio de Janeiro: Relume Dumará, 2001.

LINHARES, Juliana. Marcela Temer: bela, recatada e "do lar" - a quase primeiradama, 43 anos mais jovem que o marido, aparece pouco, gosta de vestidos na altura dos joelhos e sonha em ter mais um filho com o vice.

Veja.com. São Paulo, 18 abr. 2016. Disponível em:

<http://veja.abril.com.br/brasil/marcela-temerbela-recatada-e-do-lar/>. Acesso em: 18 jan. 2017.

LIMA FILHO, Domingos Leite. A universidade tecnológica e sua relação com o ensino médio e a educação superior: discutindo a identidade e o futuro dos CEFETs. Perspectiva. Florianópolis: v. 23, n. 02, jul./dez. 2005, p. 349-380.

Disponível em:

<https://periodicos.ufsc.br/index.php/perspectiva/article/view/9762/8992>. Acesso em: 16 jun. 2016.

LUGONES, Maria. Hacia un feminismo descolonial. La Manzana de La Discordia, Colombia, v. 6, n. 2, p. 105-119, jul./dez. 2011.

MARCHA DAS VADIAS CWB: movimento pelo fim da violência de gênero e da culpabilização da vítima. Quem somos? Disponível em:

<https://marchadasvadiascwb.wordpress.com/2016/11/04/quem-somos/>. Acesso em: 18 jan. 2017.

MARCHA DAS VADIAS CURITIBA. Página inicial. Disponível em:

<https://www.facebook.com/marchadasvadiascwb/about/>. Acesso em: 18 jan. 2017.

MENDONÇA, Renata. Assassino de Campinas atirou sozinho, mas não inventou assassinato de mulheres sozinho, diz filósofa. BBC Brasil. São Paulo, 05 jan. 2017. Disponível em: <http://www.bbc.com/portuguese/brasil-38503326>. Acesso em: 18 jan. 2017.

MUZI, Joyce Luciane Correia. LUZ, Nanci Stancki da. Entre cursos e discursos: um olhar sobre mulheres e ciência na universidade. In.: VIII CONGRESSO IBEROAMERICANO DE CIÊNCIA, TECNOLOGIA E GÊNERO. 8.. Curitiba, Anais... Curitiba, 2010. Disponível em:

<http://files.dirppg.ct.utfpr.edu.br/ppgte/eventos/cictg/conteudo_cd/E5_Entre_ Cursos_e_Discursos.pdf>.

PASINATO, WÂNIA. Criamos o discurso politicamente correto, mas nossa sociedade continua violenta: para a especialista, os crimes recentes, como a chacina de Campinas, mostram que as políticas para inibir a violência não foram efetivadas, apesar da indignação geral. [2 de janeiro, 2017]. São Paulo: El País. Entrevista concedida a Camila Moraes. Disponível em: <http://brasil.elpais.com/brasil/2017/01/02/politica/1483382488_219669.html>. Acesso em: 18 jan. 2017 
RODRIGUES, Matheus. Polícia conclui inquérito de estupro coletivo no Rio com sete indiciados. G1. Rio de Janeiro, 17 jun. 2016. Disponível em: <http://g1.globo.com/rio-de-janeiro/noticia/2016/06/policia-concluiinqueritode-estupro-coletivo-no-rio-com-sete-indiciados.html>. Acesso em: 18 jan. 2017.

ROSSI, MARINA. Machismo na política: "vaca" até quando? No dia internacional da mulher, a presidenta Dilma Rousseff é xingada e isso incomoda homens e mulheres, eleitores dela ou não. El País. São Paulo, 09 mar. 2015. Disponível em: <http://brasil.elpais.com/brasil/2015/03/09/politica/1425911342_272443.html>. Acesso em: 18 jan. 2017.

RUBIN, GAYLE. Thinking sex: notes for a radical theory of the politics of sexuality. In.: Vance, Carole (ed.). Pleasure and danger: exploring female sexuality. London: Routledge and Kegan Paul, 1985, cap. 9, p. 143-178.

SARDERNBERG, Cecília Maria Bacellar. Da crítica feminista à ciência a uma ciência feminista. In: COSTA, Ana Alice Alcântara; SARDERNBERG, Cecília Maria Bacellar (orgs). Feminismo, ciência e tecnologia: Salvador: REDOR/NEIM-FFCH/UFBA, 2002, p. 89-120.

TELES, Maria Amélia de Almeida. $\mathbf{O}$ que são direitos humanos das mulheres. São Paulo: Brasiliense, 2006.

UNIVERSIDADE TECNOLÓGICA FEDERAL DO PARANÁ. In.: LEITE, José Carlos Corrêa (org.). UTFPR: uma história de 100 anos. 2. ed. Curitiba: UTFPR, 2010.

VETTORAZZO, Lucas. BÔAS, Bruno Villas. Cresce número de mulheres chefes de família no Brasil. Folha de São Paulo. Rio de Janeiro, 04 dez. 2015. Disponível em: <http://www1.folha.uol.com.br/mercado/2015/12/1714906-proporcaodefamilias-chefiadas-por-mulheres-chega-a-40-em-2014.shtml>. Acesso em: 18 jan. 2017.

Recebido: 22 jan. 2017.

Aprovado: 06 abr. 2017

Como citar:

FERREIRA, Michel Alves..; PARINGER, T. K. C. C.; CASAGRANDE, Lindamir S. O que você já deixou de fazer por ser mulher? Relato de uma experiência. Cad. gên. Tecnol., Curitiba, v. 10, n. 35, p. 4-25, jan./jun. 2017. Disponível em: <>. Acesso em: XXX.

Correspondência:

Michel Alves Ferreira

Rua Deputado Gabriel Sampaio, 465, Apto. 22 Bloco 2, CEP 81270-090

Direito autoral:

Este artigo está licenciado sob os termos da Licença Creative Commons-Atribuição 4.0 Internacional.

\section{(c) (1)}

